

\section{Prognosis of wheezing and asthma presenting in early childhood}

\section{CME article: educational aims}

1 To identify the different types of wheezing illness in asthma that present in childhood.

$\checkmark$ To aid healthcare professionals in the discussion of medium- to long-term prognosis with parents of children presenting with wheezing illness.

1 To place prophylactic therapy in the context of the natural history of the disease.

\section{Summary}

Childhood asthma covers a wide spectrum, ranging from mild-intermittent to severe-persistent disease, with different natural histories. Female sex, age at presentation, atopic constitution, parental atopy, and severity and frequency of attacks can all be identified as risk factors for persistence into adult life, while others, including maternal smoking, prematurity and bronchiolitis of infancy, do not appear to be associated to such an extent. The use of prognostic features alongside assessment of disease severity should inform long-term clinical management and be useful in counselling the child and her/his family.

Childhood asthma is a global health problem, which exerts a substantial burden on the family, healthcare services and society, and is the leading cause of chronic illness in children living in developed economies [1].

Documented wheezing in older children generally denotes asthma, whereas wheezing in infancy is a more heterogeneous condition. Although most symptomatic infants remit by the time they reach school age, an important minority continue to suffer from persistent and life-long asthma [2]. Hence, an understanding of the natural history of asthma and wheezing illness, particularly those risk factors associated with persistence or resolution, is a prerequisite for testing the hypothesis that early therapeutic intervention may modify the long-term course of the disease. If it was decided that all children presenting with wheeze should be given prophylactic medications, up to half of all children would need to be treated. Parents of young children presenting for the first time also want to know the probable medium- to longterm outcome. It is, therefore, important for the clinician to have some knowledge of the natural history and factors associated with the resolution and persistence of asthma presenting in childhood.

\section{Asthma phenotypes}

The identification of children with asthma remains a problem, as the clinical syndrome that clinicians recognise as asthma does not

\section{P.J. Helms \\ S.S. Amin

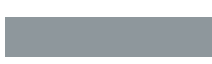 \\ Dept of Child Health, University of Aberdeen Aberdeen, UK.}

\author{
Correspondence: \\ P.J. Helms \\ Dept of Child Health \\ University of Aberdeen \\ Royal Aberdeen Children's \\ Hospital \\ Westburn Road \\ Aberdeen \\ AB25 2ZG \\ UK \\ Fax: 441224551919 \\ E-mail:p.j.helms@abdn.ac.uk
}

The ERS designates this educational activity for a maximum of one CME credit. For information on how to earn CME credit, see page 175. 


\section{Figure 1}

Different types of asthma and wheezing in infancy and childhood. develop in all children presenting with wheezing illness [3]. There are also a number of conditions and clinical presentations, particularly in infancy, that can be distinguished from each other (figure 1). More than half of all children who wheeze during the first years of life exhibit a transient condition that resolves during the pre-school and early school years. The extent of recognised conditions that can present with wheezing in infancy ranges from the so-called "happy wheezer", who is often male, overweight and more of a concern to his parents than to the infant himself, to the wheeze often seen in premature infants and following an episode of bronchiolitis. Distinctions can be made between asthma, which is usually associated with atopy and is provoked by a range of external factors, and wheezy bronchitis (viralassociated wheeze), in that the former tends to persist and the latter resolves in the transition to adult life $[4,5]$.

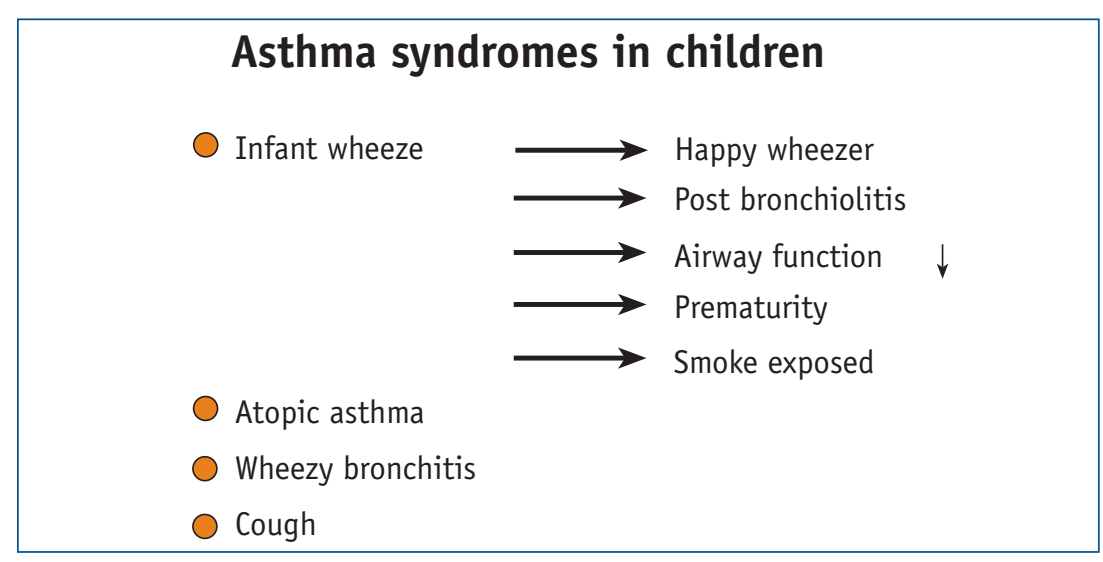

A group that has been characterised by reduced airway function present at birth and, possibly, as a result of adverse intra-uterine environmental factors has also been identified [6]. Since there is more than one phenotype in childhood, investigators have used various definitions, including a physician diagnosis of asthma, current wheeze, the presence of bronchial hyperresponsiveness (BHR), coexistent atopy or combinations of these [7].

\section{Natural history}

The natural history of asthma from childhood to adulthood has been the focus of many studies and, as a consequence, the understanding of the natural history of asthma and childhood wheezing illness. From the middle of the 20th century, an increasing number of hospital- and clinicbased and whole-population cohort studies have been reported.
The UK National Birth Cohort Study of $>18,000$ children born in March 1958 has undergone repeated surveys, with follow-ups at ages 7 , $11,16,23$ and 33 years [8-10], and in which a substantial decrease in asthma and wheezing symptoms has been noted through childhood into adolescence. When pulmonary function was measured before and after inhalation of a bronchodilator in members of this cohort, a more pronounced response was observed in those with an earlier age of wheeze onset, suggesting that the longer the duration of the disease, the greater the degree of bronchial responsiveness [8]. Perinatal factors, including maternal age, parity, birthweight for gestation and breastfeeding, were not related to persistence.

The follow-up studies from Melbourne (Australia) have been highly influential in understanding the prognosis of childhood asthma. In these studies, 7-year-old children were initially recruited in 1963 and, subsequently, followed-up into mid-adult life, with a severe symptomatic group added at age 11 years $[5,11-15]$. The original aim was to determine the prevalence and natural history of childhood asthma, and what was then termed "wheezy bronchitis" (wheeze predominantly associated with intercurrent viral infections), in comparison with an asymptomatic "control" group. Wheezy bronchitis was defined as more than five prior episodes of wheezing with infections, and mild wheezy bronchitis as less than five such episodes. In symptomatic children, $50 \%$ reported their first wheezing illness before 3 years of age and $18 \%$ in the 1st year of life. Although these studies found a significant association between early age of onset, frequency of attacks in the first year of symptoms and persistence of asthmatic episodes up to 10 years, it should be remembered that children were recruited at age 7 years and that, as a subsequent whole population birth cohort has shown, the majority of early-presenting wheezing children will become asymptomatic by age 6 years [6]. At the age of 35 years, the lung function of those with mild childhood wheezy bronchitis was indistinguishable from the asymptomatic group, with a gradient of impairment for the other categories that depended on their initial assessment of severity in childhood and that has been shown to be associated with "tracking" of function throughout life $[14,16]$.

The Dunedin (New Zealand) cohort, which was established in 1972-1973, followed clinical features, lung function and BHR at 9, 11, 13, 15, 18,21 and 26 years of age [17]. In this cohort, the 
prevalence of diagnosed asthma varied by age between 10 and $20 \%$, and was initially more common in young males, with a subsequent switch to a predominance in young females. The prevalence of BHR was higher in childhood than in adolescence [17].

The Tasmanian (Australia) birth cohort of 8,410 children was designed to compare the natural histories of wheeze and productive cough [18-20]. Of those diagnosed with asthma at age 7 years, one in four had current asthma as an adult and one in 20 had frequent asthma. Of those who were asymptomatic at age 7 years, $10 \%$ had developed asthma and $2 \%$ frequent asthma in early adulthood. In addition to childhood asthma, risk factors for adult asthma were found to be: impaired lung function in childhood, female sex, coexistent eczema, and a history of maternal and/or paternal asthma.

The Tucson Children's Respiratory Study (AZ, USA) found that children who had wheezed before 3 years of age but not at 6 years (transient wheezers), who had diminished airway function in the 1st year of life and at 6 years of age, were more likely to have mothers who smoked, negative skin-prick tests to common inhaled allergens and normal serum immunoglobulin $(\mathrm{Ig}) \mathrm{E}$ than those with persistent symptoms [6, 21-25].

From such studies in symptomatic and whole populations, it appears that $30 \%$ of 3-year-old children will have had at least one acute episode of wheezing, $60-70 \%$ will outgrow their wheeze by $6-8$ years of age and much of the mild wheezing in young non-atopic children may be explained by subtle impairments of airway function that were probably present at birth. Other conclusions that can be drawn from the wealth of available studies, and reviewed in more detail below, are as follows: up to $50 \%$ of young adults (in their early 20s) who were categorised as childhood asthmatics will be asymptomatic; baseline

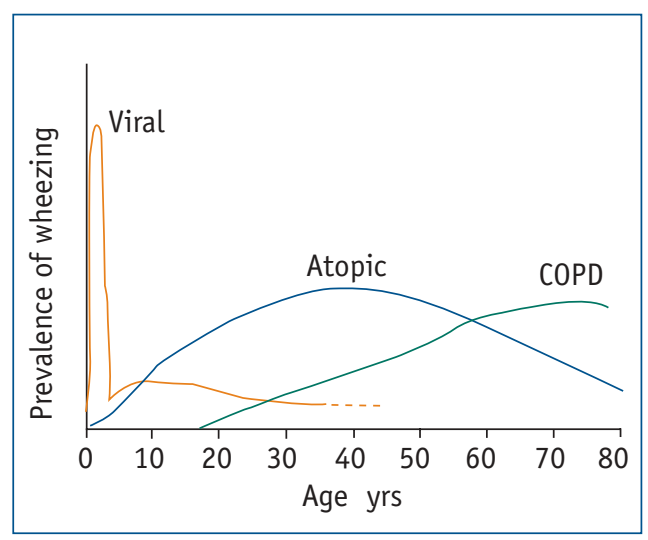

lung function is likely to track along the same centiles with growth; and airway responsiveness in childhood is likely to predict airway responsiveness and symptoms of asthma in adulthood. Whilst the natural history of asthma and wheezing illness can be followed from childhood through adolescence into early- and mid-adult life, the natural history across the whole life span is complicated by the later emergence of irreversible chronic obstructive lung disease (COPD) (figure 2).

\section{Sex differences}

Whole population studies consistently show an earlier age of presentation and a higher prevalence of asthma in pre- and peri-pubertal males than females [26]. The higher prevalence of asthma in young males may be explained by a combination of factors, including a smaller peripheral airway calibre before puberty $[27,28]$ and an increased prevalence of atopy and a higher prevalence of BHR [26].

In pre-school children, the cumulative prevalence of diagnosed asthma increases with age, although the male predominance is evident throughout this early period of life [29]. In children aged 5-9 years, the male predominance is still present, although males have been noted to present at an earlier age than females and with less severe disease [30]. Later in childhood and towards puberty, there appears to be a gradual shift to an increased prevalence and severity of asthma in young females [31], changes that continue into early adult life [19].

Follow-up of the Tucson birth cohort to 13 years found that, during the first 3 years of life, males were more likely than females to be early wheezers, early frequent wheezers and to have wheezing apart from colds. The prevalence of asthma was significantly higher in males than in females at all ages up to 11 years of age, but not at 13 years $[6,21-23]$. In the Melbourne followup studies, a history of wheeze in the past 12 months was more common in 7-year-old males than females, a sex difference that became less obvious at 12 years and that had disappeared by 15 years. Subsequent follow-up at 21 years showed that this pattern persisted and that the male predominance of severe disease was lost by this age $[5,12,14,15]$. The British Birth Cohort study also found a similar sex reversal between 16 and 23 years [9], as did a similar New Zealand cohort [17].

In adult populations, the male:female ratio is about 1:1.5 [26,32], differences that could be
Figure 2

Types of wheezing illness over the lifespan and their relative contribution at different ages. 
In summary, the natural history of wheeze is dependent on the age at first presentation, in that the earlier the child presents, the better the prognosis. From the data available from prospective birth cohorts and from hospital populations, an apparent "break point" can be seen at around 2 years, with the majority of those presenting before this age becoming asymptomatic by mid-childhood (6-11 years).

\section{Parental smoking}

A number of studies have shown that exposing the foetus to the products of cigarette smoke leads to decreased lung function, increased risks of episodes of airway obstruction and airway hyperresponsiveness in the newborn period [42-46]. In general, it appears that maternal smoking is more deleterious than paternal smoking, which is consistent with greater effects of prenatal exposure [46].

In addition to the association between maternal smoking and transient early wheezing, exposed infants have significantly lower airway function than non-exposed infants [6]. An apparent dose effect for asthma in early life has also been noted [25]. In the British Birth Cohort, maternal smoking was associated with frequency of wheezing in mid-childhood, although this association was no longer present for asthma and/or wheezy bronchitis at age 16 years [9]. Similar results have also been reported from New Zealand [17], although these effects appear to reduce with increasing child age [47], are stronger for persistent than for late-onset wheezing [48] and are still evident at 13 years of age [49].

Overall, the available studies suggest that maternal smoking has a significant and independent contribution to repeated wheezing illnesses in childhood, but with diminishing effects with subsequent growth and development.

\section{Respiratory infections}

The relationship between lower respiratory tract infections in infants and children and the subsequent development of asthma is controversial $[50,51]$. Viral infections, particularly those caused by respiratory syncytial virus (RSV), occur frequently in children and often cause wheezing in children both with and without asthma. The possibility that RSV and other viruses can interact with the immune and respiratory systems in subjects who are genetically predisposed to initiate the complex pathogenic mechanism leading to asthma has been the focus of considerable study and debate $[2,52]$.

In a Swedish follow-up study of infants hospitalised with RSV bronchiolitis in early infancy (mean age of 3.5 months), RSV bronchiolitis was found to be the dominant factor for the development of future obstructive symptoms at age 3 years, the highest independent risk ratio for asthma at age 7 years and a significantly independent risk for allergic sensitisation $[53,54]$. This was not, however, confirmed in a similar follow-up study from Newcastle (UK) [55].

Most follow-up studies have been performed in children who had been admitted to hospital as infants with moderate-to-severe bronchiolitis. Follow-up at 8 and 13 years have found that, although mild bronchiolitis is a powerful predictor of wheezing at age of 8 years, it is only a weak and non-statistically significant predictor of wheezing at age 13 years [49]. Similar conclusions have also been drawn from the Tucson whole population birth cohort, in that RSV bronchiolitis before 3 years was associated with a significant increase in the risk of subsequent wheezing during the first 10 years of life, but decreased with age and was no longer significant by age 13 years $[23,24]$.

Although there is evidence of an association between early respiratory infections and RSV infections in particular, it appears that this association weakens with advancing age. Long-term outcome into adult life is unknown.

\section{Coexistent atopic disease}

Cross-sectional and longitudinal studies have shown strong associations between asthma and wheezing and atopy, defined as either the presence of eczema and hay fever and/or total serum $\lg \mathrm{E}$ and specific allergen sensitisation. The observation that both eczema and hay fever are strongly related to current asthma in early adult life suggests that it is the degree of susceptibility to all forms of atopic disease that drives the development of asthma during childhood and adolescence [56].

Children with transient early wheezing and those who had never wheezed have been found to have similar serum IgE levels and similar prevalences of atopic disease at the age of 6 years, in contrast to the significantly higher levels of IgE in those with persistent wheezing [6]. Wheezing in mid-childhood that is strongly associated with atopy is also seen in the Poole (UK) cohort [39]. The majority of children with asthma also report either coexistent eczema or hay fever [57], and 


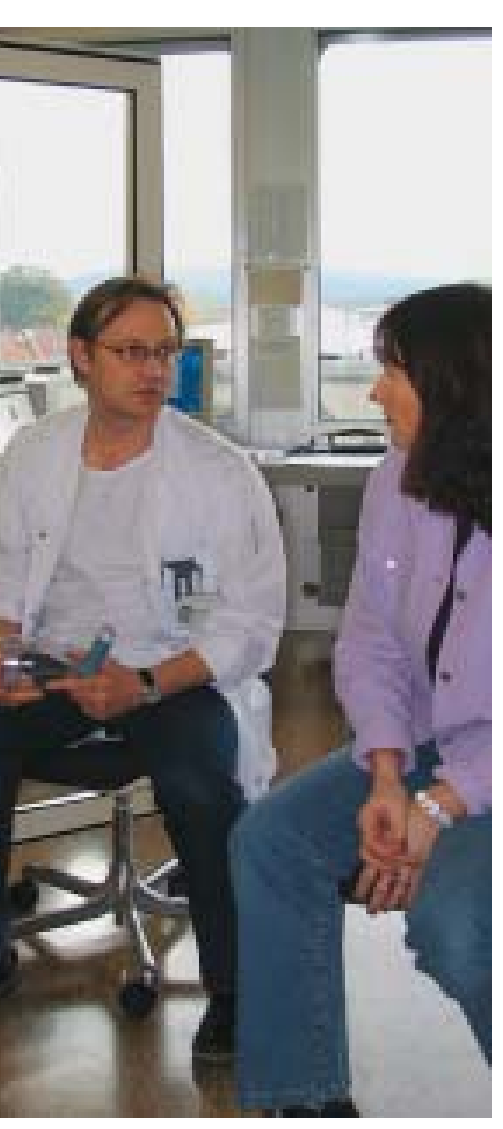

this has been consistently reported from one of the earliest reported studies [34].

Long-term follow-up has also confirmed that coexistent hay fever, eczema or skin-test reactivity to relevant inhalant allergens are associated with the risk of more severe asthma in adulthood [15]. In early childhood, there is a relationship between atopy and the probability of wheeze [58], and similar associations have been noted during adolescence [59]. Unlike other associations, one of the older studies found similar associations, in that the presence of eczema and/or hay fever was related to severe and persistent asthma [34]. Whilst infantile eczema does not appear to be associated with the persistence of asthma [35, 57], hay fever is a strong associated risk for persistence [35].

With the exception of infantile eczema, the presence of coexisting eczema and/or rhinitis are associated with increased risks of persistent disease.

\section{Family history of atopy}

In addition to the expression of atopy in the individual, there are clear risks of asthma persistence that can be attributed to a family history of atopy. Children with wheezing in early life and persistence at the age of 6 years are more likely than asymptomatic children to have mothers with a history of asthma and are almost three times more likely to have acquired a physician diagnosis of asthma [6].

In children followed up to age 18 years, the strongest predictor for atopy, airway hyperresponsiveness and symptoms of asthma is a family history of asthma and atopy, especially maternal asthma and atopy [17]. Maternal asthma is strongly associated with wheeze in infancy and early childhood [47,48], and a history of asth$\mathrm{ma}$ in both parents nearly doubles the risk for asthma and rhinitis [47].

Just as for a personal history of atopy, a family history in first-degree relatives was found to be related to persistence of asthma in one of the oldestfollow-up studies [34]. However, although the association between maternal asthma and atopy and childhood asthma is strong, the association weakens within the transition to adult life and, in one study, only remained significant in young females [59].

Asthma is strongly associated with a family history of atopy and particularly with maternal asthma, although the strength of the maternal effect appears to weaken in the transition to adult life.

\section{Severity and frequency of episodes}

The frequency of wheezing episodes in childhood has been found to be an important predictor of asthma persistence through childhood and into adulthood.

In the Poole cohort, children with persistent wheezing were distinguished during infancy by the greater frequency of their wheezing episodes [39]. The Tuscon cohort also demonstrated similar associations, in that children with persistent wheezing were more likely to have wheezed often or very often when compared to those with transient wheeze [6]. Similar observations have been made in the Avon cohort, in that the more frequent attacks children had in infancy, the less likely they were to be symptom-free at 10 years [41]. Similar features have been reported for persistence into adulthood [12, 15, 19, 60], and the oldest reported long-term follow-up study also concluded that severe childhood asthma predisposed to chronic persistent adult disease [34].

Children with frequent and severe episodes are more likely to persist with symptoms through childhood and into adult life.

\section{Lung function measurements}

Although it is commonly held that the airways obstruction in children with asthma is completely reversible, numerous studies have demonstrated persistent functional abnormalities in both children and young adults with asthma [26].

From their studies of the long-term outcome of early childhood wheezing, Strachan and Gerritsen [56] suggested that BHR and reduced levels of ventilatory function in childhood predict both persistence of wheeze and the degree of BHR in adult life. Children whose wheeze persists from the pre-school period have also been shown to have the poorest ventilatory function, the highest bronchial responsiveness and highest peak expiratory flow variability $[6,58]$.

Baseline lung function may also be predictive of the subsequent expression of asthma in asymptomatic individuals. The Tasmanian asthma surveys, for example, showed that baseline lung function in childhood is predictive of asthma in adulthood [30].

BHR in asymptomatic subjects may also be an important risk factor for the subsequent development of asthma, and many subjects with chronic persistent asthma have significant lung function deficits that are not always reversible [61]. These observations raise the possibility that there may be an irreversible component to chronic persistent 


\section{Table 1 Prognostic factors for asthma and wheezing illness from childhood to adulthood}

\begin{tabular}{|lll|}
\hline Persistence & Resolution & Uncertain \\
Female & Male & Prematurity \\
Onset <2 years & Onset >2 years & Bronchiolitis \\
Personal atopy & & Family atopy \\
Severe disease & & Maternal smoking \\
Bronchial hyperresponsiveness & & \\
\hline
\end{tabular}

asthma, and that the assessment of airway function and BHR may have a role in assessing the likelihood that the disease may continue through childhood and into adulthood.

\section{Conclusions}

Although wheezing in older children generally denotes asthma, wheezing in infancy is a heterogeneous condition (figure 1). On the one hand, most infants who wheeze will remit by the time they reach school age, but, on the other hand, in an important minority, respiratory symptoms occurring in early life may be the first manifestation of life-long asthma.

In spite of the widely held belief that early use of inhaled corticosteroids may reduce the risk of a child progressing to chronic asthma in adult life, there continue to be some concerns about the occurrence of side-effects with their long-term use. Hence, a clear understanding of the natural history of asthma and wheezing illness, and, in particular, those risk factors associated with persistence or resolution (table 1), is a prerequisite for testing the hypothesis that early therapeutic intervention may modify the long-term course of the disease.

Studies of the natural history of asthma in children demonstrate that approximately $30 \%$ of 3 -year-old children will have at least one acute episode of wheezing and that up to $60 \%$ of symptomatic children will outgrow their wheeze by 6-8 years. Male sex, low birth weight, onset of wheeze before 2 years of age, parental smoking and respiratory infections tend towards a good prognosis into adulthood, whereas female sex, onset of wheeze after 2 years of age, coexistence of atopic disease, family history of atopy, severe and frequent episodes, and impaired baseline lung function tend towards a poor prognosis into adulthood.

Therapeutic decisions, particularly the introduction of prophylactic treatment, should benefit from a better understanding of the underlying pathophysiology and the natural history of the disease. An evidenced-based approach to diagnosis, prognosis and disease management, and on which much of the present review is based is available, as a web resource (www.sign.ac.uk/). 


\section{Useful web links}

www.ginasthma.com/

www.sign.ac.uk/guidelines/ published/support/guideline63/ download.html

\section{Educational questions (Answers on page 140)}

Are the following statements true or false?

1. In childhood asthma and wheezing illness:

a) Presentation in infancy ( $<1$ year) has a poor long-term prognosis.

b) Most prospective birth cohorts demonstrate that up to $60 \%$ of children presenting in early childhood are asymptomatic by the age of $6-7$ years.

c) Rhinitis is associated with an increased risk of persistent wheeze.

d) Girls tend to present at an earlier age than boys.

e) Infantile eczema is associated with a poor long-term prognosis.

f) Non-specific bronchial hyperresponsiveness is a recognised risk factor for persistence of symptoms.

2. With regard to exposure to environmental tobacco smoke (ETS) and its contribution to childhood asthma and wheezing illness:

a) The main effects are seen in mid-to-late childhood.

b) Exposure during pregnancy is the most clearly identified influence.

c) Contributes to the expression of disease by affecting airway development in utero.

d) Breastfeeding is the main route of exposure.

e) Does not increase the risk of persistence into adult life.

3. In symptomatic children and in the transition from childhood to adult life:

a) Baseline lung function shows a progressive decline.

b) Female sex is a risk factor for progressive severe disease.

c) A history of RSV bronchiolitis in infancy is associated with severe persistent disease.

d) Maternal atopy is a strong predictor of continuing symptoms.

e) Low birthweight is not relevant to disease persistence.

\section{References}

1. Global Initiative for Asthma. www.ginasthma.com/

2. Martinez FD, Helms PJ. Types of asthma and wheezing. Eur Respir J 1998; 12: Suppl. 27, 3s-8s.

3. Larsen GL. Differences between adult and childhood asthma. J Allergy Clin Immunol 2000; 106: Suppl. 3, S153-S157.

4. Godden DJ, Ross S, Abdalla M, et al. Outcome of wheeze in childhood: symptoms and pulmonary function 25 years later. Am J Respir Crit Care Med 1994; 149: 106-112.

5. Martin AJ, Mclennan LA, Landau LI, Phelan PD. The natural history of childhood asthma to adult life. BMJ 1980; 280: 1397-1400.

6. Martinez FD, Wright AL, Taussig LM, Holberg CJ, Morgan WJ. Asthma and wheezing in the first six years of life. N Engl J Med 1995; 332: 133-138.

7. Warner JO, Pohunek $P$, Clough JB. Issues in understanding childhood asthma. J Allergy Clin Immunol 2000; 105: 272-276.

8. Strachan DP, Butland BK, Anderson HR. Incidence and prognosis of asthma and wheezing illness from early childhood to age 33 in a national British cohort. BMJ 1996; 312: 1195-1199.

9. Lewis S, Butland B, Strachan D, Richards D, Britto Jr. Study of the aetiology of wheezing illness at age 16 in two national British birth cohorts. Thorax 1996; 51: 670-676.

10. Anderson $H R$, Pottir AC, Strachan DP. Asthma from birth to age 23: incidence and relation to prior and concurrent atopic disease. Thorax 1992; 47: 537-542.

11. Williams H, McNicol KN. Prevalence, natural history, and relationship of wheezy bronchitis and asthma in children. An epidemiological study. BMJ 1969; 4: 321-325.

12. Martin AJ, Landau LI, Phelan PD. Asthma from childhood at age 21: the patient and his disease. BMJ 1982; 284: 380-382.

13. Robertson CF, Heycock E, Bishop J, Olinsky A, Phelan $P D$. Prevalence of asthma in Melbourne schoolchildren: changes over 26 years. BMJ 1991; 302: 1116-1118.

14. Oswald $H$, Phelan PD, Olinsky A. Outcome of childhood asthma in mid adult life. BMJ 1994; 309: 95-96.

15. Wolfe $R$, Carlin JB, Phelan PD, Robertson CF. Association between allergy and asthma from childhood to middle adulthood in an Australian cohort study. Am J Respir Crit Care Med 2000; 162: 2177-2181.

16. Horak E, Lanigan A, Roberts $M$, et al. Longitudinal study of childhood wheezy bronchitis and asthma: outcome at age 42. BMJ 2003; 326: 422-423.

17. Sears MR, Holdaway MD, Silva PA. Parental and neonatal risk factors for atopy, airway hyper-responsiveness, and asthma. Arch Dis Child 1996; 75: 392-398.

18. Giles GG, Lickiss N, Gibson HB, Shaw K. Respiratory symptoms in Tasmanian adolescents: a follow up of 1961 cohort. Aust N Z J Med 1984; 14: 631-637.

19. Jenkins MA, Hopper JL, Giles GG. Factors in childhood as predictor of asthma in adult life. BMJ 1994; 309: 90-93.

20. Ponsonby AL, Couper D, Carmichael A. Cross sectional study between the relation between sibling number and asthma, hay fever, and eczema. Arch Dis Child 1998; 79: 328-333.

21. Castro-Rodriguez JA, Holberg CJ, Wright AL, Martinez $F D$. A clinical index to define risk of asthma in young children with recurrent wheezing. Am J Respir Crit Care Med 2000; 162: 1403-1406.

22. Stein RT, Holberg $C J$, Wright $A L$, et al. Influence of parental smoking on respiratory symptoms during the first decade of life. Am J Epidemiol 1999; 149: 1030-1037.

23. Dodge R, Martinez FD, Cline MG, Lebowitz MD, Burrows 
B. Early childhood respiratory symptoms and the subsequent diagnosis of asthma. J Allergy Clin Immunol 1996; 98: 45-54.

24. Stein RT, Sherrill D, Morgan WJ, et al. Respiratory syncytial infection in early life and risk of wheeze and allergy by age 13 years. Lancet 1999; 354: 541-545.

25. Martinez FD, Cline M, Burrows B. Increased incidence of asthma in children of smoking mothers. Pediatrics 1992; 89: 21-25.

26. Roorda RJ. Prognostic factors for the outcome of childhood asthma in adolescence. Thorax 1996; 51: Suppl. 1, S7-S12.

27. Hibbert M, Lannigan A, Raven J, Landau L, Phelan P. Gender differences in lung growth. Pediatr Pulmonol 1995; 19: 129-134.

28. Rosenthal M, Bain SH, Cramer D, et al. Lung function in white children aged 4 to 19 years: I - Spirometry. Thorax 1993; 48: 794-802.

29. Luyt DK, Burton P, Simpson H. Epidemiological study of wheeze, doctor diagnosed asthma, and cough in preschool children in Leicestershire. BMJ 1993; 306: 1386-1390.

30. Sherman CB, Tosteson TD, Tager IB, Speizer FE, Weiss ST. Early childhood predictors of asthma. Am J Epidemiol 1990; 132: 83-94.

31. Aberg N, Engstrom I. Natural history of allergic disease in children. Acta Paediatr Scand 1990; 79: 206-211.

32. Loar A, Cohen L, Danon YL. Effects of time, sex, ethnic origin, and area of residence on prevalence of asthma in Israeli adolescents. BMJ 1993; 307: 841-844.

33. Roorda RJ, Gerritsen J, Van Aalderen WMC, et al. Risk factors for the persistence of respiratory symptoms in childhood asthma. Am Rev Respir Dis 1993; 148: 1490-1495.

34. Blair H. Natural history of childhood asthma. Arch Dis Child 1977; 52: 613-619.

35. Johnstone $D E$, Rochester NY. A study of the natural history of asthma in children. Am J Dis Child 1968; 115: 213-217.

36. Shaheen SO, Sterne JAC, Montgomery SM, Azima H. Birth weight, body mass index and asthma in young adults. Thorax 1999; 54: 396-402.

37. Gross SJ, Iannuzzi DM, Kveselis DA, Anbar RD. Effect of preterm birth on pulmonary function at school age: $a$ prospective controlled study. J Pediatr 1998; 133: 188-192.

38. Clough JB, Keeping $K A$, Edwards $L C$, Freeman WM, Warner JA, Warner J0. Can we predict which wheezy infant will continue to wheeze? Am J Respir Crit Care Med 1999; 160: 1473-1480.

39. Sporik R, Holgate ST, Cogswell JJ. Natural history of asthma in childhood: a birth cohort study. Arch Dis Child 1991; 66: 1050-1053.

40. Boesen I. Asthmatic bronchitis in children. Prognosis for 162 cases, observed 6-11 years. Acta Pediatr 1953; 42: 87-96.

41. Park ES, Golding G, Carswell F, Stewart-Brown S. Preschool wheezing and diagnosis at 10 years. Arch Dis Child 1986; 61: 642-646.

42. Joad JP. Smoking and pediatric respiratory health. Clin Chest Med 2000; 21: 37-46, vii-viiii.

43. Ehrlich RI, Toit DD, Jordaan E, et al. Risk factors for childhood asthma and wheezing. Am J Respir Crit Care Med 1996; 154: 681-688.

44. Austin JB, Russell G. Wheeze, cough, atopy, indoor environment in the Scottish Highlands. Arch Dis Child 1997; 76: 22-26.

45. Wang X, Wypij D, Gold DR, et al. A longitudinal study of the effect of parental smoking in children 6-18 years. Am J Respir Crit Care Med 1994; 149: 1420-1425.

46. Lux AL, Henderson AJ, Pocock SJ, and the ALSPAC Study Team. Wheeze associated with prenatal tobacco smoke exposure: a prospective, longitudinal study. Arch Dis Child 2000; 83: 307-312.

47. Tariq SM, Mathews SM, Hakim EA, Stevens M, Arshad $S H$, Hide DW. The prevalence and risk factors for atopy in early childhood: a whole population birth cohort study. Clin Immunol 1998; 101: 587-593

48. Rusconi F, Galassi C, Corbo GM, et al. Risk factors for early, persistent, and late onset wheezing in young children. Am J Respir Crit Care Med 1999; 160: 1617-1622.

49. Mcconnochie KM, Roghmann KJ. Wheezing at 8 and 13 years: changing importance of bronchiolitis and passive smoking. Pediatr Pulmonol 1989; 6: 138-146.

50. Martinez FD. Maturation of immune responses at the beginning of asthma. J Allergy Clin Immunol 1999; 103: 355-361.

51. von Mutius $E$. The burden of childhood asthma. Arch Dis Child 2000; 82: Suppl. 2, ii2-iï.

52. Kneyber MCJ, Steyerberg EW, Groot RD, Moll HA. Long term effect of respiratory syncytial virus (RSV) bronchiolitis in infants and young children: a quantitative review. Acta Paediatr 2000; 89: 654-660.

53. Sigurs $N$, Bjaranason $R$, Sigurbergsson F, Kjellman $B$. Respiratory syncytial virus bronchiolitis in infancy is an important risk factor for asthma and allergy at age 7. Am J Respir Crit Care Med 2000; 161: 1501-1507.

54. Sigurs N, Bjaranason R, Sigurbergsson F, Kjellman B, Bjorksten B. Asthma and immunoglubulin $E$ antibodies after respiratory syncytial virus bronchiolitis: a prospective cohort study with matched controls. Pediatrics 1995; 95: 500-505.

55. Sims DG, Downham MAPS, Gardner PS, Webb JKG, Whightman D. Study of 8-year-old children with a history of respiratory syncytial virus in infancy. BMJ 1978; 1: $11-14$.

56. Strachan D, Gerritsen J. Long-term outcome of early childhood wheezing: population data. Eur Respir J 1996; 9: S42-S47.

57. Austin JB, Kaur B, Anderson HR, et al. Hay fever, eczema, and wheeze: a nationwide UK study (ISAAC, international study of asthma and allergy in children). Arch Dis Child 1999; 81: 225-230.

58. Brooke AM, Lambert PC, Burton PR, Clarke C, Luyt DK, Simpson $H$. The natural history of respiratory symptoms in preschool children. Am J Respir Crit Care Med 1995; 52: 1872-1878.

59. Withers NJ, Low L, Holgate ST, Clough JB. The natural history of respiratory symptoms in a cohort of adolescents. Am J Respir Crit Care Med 1998; 158: 352-357.

60. Kjellman B, Hesselmar B. Prognosis of asthma in children: a cohort study into adulthood. Acta Paediatr 1994; 83: 854-861.

61. Urlik CS, Backer V, Hesse B, Dirksen A. Risk factors for development of asthma in children and adolescents: findings from a longitudinal population study. Respir Med 1996; 90: 623-630. 


\section{Suggested answers}

1. a) False.

b) True.

c) True. In follow-up studies from mid-childhood into adult life, coexistent atopic disease and, in particular, rhinitis are associated with persistent disease. This is arguably an example of what has been termed "the united airway", in that the underlying mechanisms within the upper respiratory and lower respiratory tract are likely to be similar.

d) False. Prospective birth cohorts clearly show that boys are in the majority of early presenters and that the proportion of presenting females increases significantly throughout childhood and into early adult life.

e) False. Although the concept of "the allergic march" may be true for a limited number of infants from high-risk families, infantile eczema is common and is the one atopic disease that is notstrongly associated with persistent asthma and wheezing illness. Infantile eczema is also likely to include a very wide range of transient skin rashes that may not be truly eczematous.

f) True. Follow-up studies from mid-childhood into adult life clearly show that bronchial hyperresponsiveness persists into adult life and is associated with the later expression of wheezing illness and/or persistence of wheezing symptoms.

2. a) False. Infants so exposed have increased risks of recurrent respiratory symptoms in infancy and early childhood. This is presumably the consequence of increased exposure in pregnancy and in early childhood, particularly from mothers who smoke.

b) True. Studies where children have been recruited in utero show this effect.

c) True. Several studies have demonstrated this effect, in that physiological indices of airflow obstruction in infancy and before expression of wheezing illness are related to ETS exposure. This effect is likely to be due to subtle adverse effects on airway development in utero.

d) False. The main route of exposure is in utero and, subsequently, by the inhaled route. Infants and young children have large ventilatory turnovers as a consequence of their increased metabolic rate. The obligate close association with their carers means that the main route of exposure after delivery is by inhalation.

e) True. The effect is predominantly one of close association with smoking carers, usually the mother. As the child grows and develops and becomes more independent, the level of exposure reduces. However, it needs to be remembered that children of parents who smoke are more likely to smoke themselves; hence, the risk of personal exposure will be increased in smoking families.

3. a) False. Long-term follow-up studies from childhood into mid-adult life show "tracking" of lung function in association with disease severity. Although a progressive decline in association with "airway remodelling" seems logical, this is not borne out by the long-term follow-up studies currently available.

b) True. Young females who have had a history of asthma from childhood are more likely to have severe disease in the transition to adult life. The reasons for this are not entirely clear, but are likely to be associated with hormonal influences on immune responses and on airway and lung development.

c) False. The association is with persistent disease in early to mid-childhood, which becomes less obvious in early adolescence.

d) False. Whereas maternal history of atopy and particularly asthma is a risk factor for childhood asthma and wheezing illness, the strength of this association becomes weaker in the transition to adult life. This may be a consequence of the gradual decline of interuterine influences with subsequent growth.

e) True. The associations that have been reported with late-presenting adult chronic obstructive lung disease may operate through a different mechanism. Whereas birthweight per se does not appear to have a significant influence on asthma in the child-to-adult transition, extreme prematurity and chronic lung disease prematurity, including bronchopulmonary dysplasia, may become more significant with the increasing survival of extremely premature infants as a consequence of advances in neonatal intensive care. 